\title{
Multicenter Phase II Trial of Temozolomide in Patients With Anaplastic Astrocytoma or Anaplastic Oligoastrocytoma at First Relapse
}

\author{
By W.K. Alfred Yung, Michael D. Prados, Ricardo Yaya-Tur, Steven S. Rosenfeld, Michael Brada, Henry S. Friedman, \\ Robert Albright, Jeffrey 0 Ison, Susan M. Chang, Alison M. O 'N eill, Allan H. Friedman, Janet Bruner, Nancy Yue, \\ Margaret Dugan, Sara Zaknoen, and Victor A. Levin for the Temodal Brain Tumor Group
}

\begin{abstract}
Purpose: To determine the antitumor efficacy and safety profile of temozolomide in patients with malignant astrocytoma at first relapse.

Patients and Methods: This open-label, multicenter, phase II trial enrolled 162 patients (intent-to-treat [ITT] population). After central histologic review, 111 patients were confirmed to have had an anaplastic astrocytoma (AA) or anaplastic mixed oligoastrocytoma. Chemotherapy-naive patients were treated with temozolomide $200 \mathrm{mg} / \mathrm{m}^{2} / \mathrm{d}$. Patients previously treated with chemotherapy received temozolomide $150 \mathrm{mg} /$ $\mathrm{m}^{2} / \mathrm{d}$; the dose could be increased to $200 \mathrm{mg} / \mathrm{m}^{2} / \mathrm{d}$ in the absence of grade $3 / 4$ toxicity. Therapy was administered orally on the first 5 days of a 28-day cycle.

Results: Progression-free survival (PFS) at 6 months, the primary protocol end point, was $46 \%$ (95\% confidence interval, $38 \%$ to $54 \%$ ). The median PFS was 5.4 months, and PFS at 12 months was $24 \%$. The median overall survival was 13.6 months, and the 6- and
\end{abstract}

$\mathbf{M}$ ALIGNANT ASTROCYTOMAS account for approximately $60 \%$ of all primary brain tumors in adults. They are associated with a high rate of recurrence after primary therapy and a high mortality rate. Median survival does not exceed 3 to 4 years from initial diagnosis. Malignant astrocytomas can be further separated into two grades, anaplastic astrocytoma (AA) and glioblastoma multiforme (GBM), based on histology. ${ }^{1,2}$ GBMs tend to occur

From the University of Texas M.D. Anderson Cancer Center, Houston, TX; University of California, San Francisco, San Francisco, CA; University of Alabama, Birmingham, AL; Duke University, Durham, NC; University of Cincinnati, Cincinnati, OH; Emory Clinic, Atlanta, GA; Johns Hopkins University, Baltimore, MD; Schering-Plough Pharmaceuticals, Kenilworth, NJ; Hôpital de la Pitié-Salpetrière, Paris, France; and Royal Marsden Hospital, Surrey, United Kingdom. Submitted December 15, 1998; accepted April 22, 1999.

Supported in part by grants from Schering-Plough Research Institute (SPRI), Kenilworth, NJ. A.Y., M.P., M.B., H.F., N.Y., and V.L. are consultants to SPRI and have received honoraria from speaking engagements sponsored by SPRI.

Address reprint requests to W.K. Alfred Yung, MD, University of Texas M.D. Anderson Cancer Center, Department of Neuro-oncology, Box 100, 1515 Holcombe Blvd, Houston, TX 77030; email yung@ manderson.org.

(1) 1999 by American Society of Clinical Oncology.

0732-183X/99/1709-2762 12-month survival rates were $75 \%$ and $56 \%$, respectively. The objective response rate determined by independent central review of gadolinium-enhanced magnetic resonance imaging scans of the ITT population was $35 \%$ (8\% complete response [CR], $27 \%$ partial response [PR]), with an additional $26 \%$ of patients with stable disease (SD). The median PFS for patients with SD was 4.4 months, with $33 \%$ progression-free at 6 months. Maintenance of progression-free status and objectively assessed response (CR/PR/SD) were both associated with health-related quality-of-life (HQL) benefits. Adverse events were mild to moderate, with hematologic side effects occurring in less than $10 \%$ of patients.

Conclusion: Temozolomide demonstrated good single-agent activity, an acceptable safety profile, and documented HQL benefits in patients with recurrent AA.

J Clin Oncol 17:2762-2771. () 1999 by American Society of Clinical Oncology.

in a slightly older population and carry a worse prognosis than AAs. Historically, the neuro-oncology community has not separated the treatment of patients with recurrent malignant astrocytomas into the two histologic subtypes. The standard of care for primary disease in both histologic groups has been surgery and radiation therapy; adjuvant chemotherapy is still controversial. The studies by Levin et $\mathrm{al}^{3}$ have suggested a benefit from postradiotherapy adjuvant chemotherapy with procarbazine, lomustine, and vincristine (PCV) in patients with AA. No standard of care exists for recurrent disease. A recent systematic review of the literature on recurrent high-grade glioma identified only the nitrosoureas as active agents, but their usefulness at recurrence is limited by the presence of toxicities resulting from previous administration (reviewed by Rodriguez and Levin ${ }^{4}$ ). Therefore, new agents with a favorable toxicity profile are needed for patients with recurrent AA.

Temozolomide is an alkylating agent that has demonstrated clinical antitumor activity ${ }^{5-9}$ and a relatively welltolerated safety profile in phase I and phase II trials in patients with various advanced cancers, including malignant gliomas. ${ }^{9,10}$ Temozolomide is rapidly absorbed after oral administration and undergoes spontaneous hydrolysis at physiologic $\mathrm{pH}$ to its active metabolite 3-methyl-(triazen-1yl)imidazole-4-carboxamide (MTIC) ${ }^{5,11}$ The mechanism of 
action of MTIC is thought to be alkylation at the O6 position of guanine, with additional alkylation at the N7 position. ${ }^{12,13}$ Both in nonhuman primate models and in one human melanoma patient, the concentration of temozolomide measured in CSF is approximately $35 \%$ to $39 \%$ of that measured in plasma. Additionally, temozolomide achieves higher levels in human astrocytoma compared with contralateral normal brain. ${ }^{14}$ The antitumor activity and favorable side effect profile of temozolomide have prompted the evaluation of this chemotherapeutic agent in the present multicenter trial of patients with AA at first relapse.

\section{PATIEN TS AND METHODS}

\section{Study Design}

The present study was an open-label, single-arm, multicenter phase II trial designed to evaluate the antitumor efficacy and safety profile of temozolomide in patients with AA at first relapse. Thirty-two centers (15 in the United States and 17 internationally) participated in the study. The primary objective of this trial was to evaluate progression-free survival (PFS) at 6 months and the safety of temozolomide in treated patients. This short primary end point was selected because a companion GBM trial was performed at the same time. All investigators concurred that a 6-month end point was appropriate in the GBM setting because, at that time, most patients failed to respond to the drug. It was also agreed to use a similar end point in the present trial for the purpose of comparison and to ensure uniformity of trial design. The secondary objectives were the evaluation of overall survival and the determination of health-related quality of life (HQL) and population pharmacokinetics. The original enrollment goal was 100 patients with central review-confirmed eligible histology. However, as enrollment continued during histology evaluation, the final number of patients with eligible histologies was 111, with 162 potential candidates enrolled in the intent-to-treat population.

\section{Patient Eligibility}

In this trial, patients were required to demonstrate histologically proven, supratentorial anaplastic glioma at first relapse, as assessed by independent central pathology review of all pathology slides (J.B.) based on the three-tiered system of Nelson et al and Burger et al. ${ }^{1,2}$ Histologic criteria included the presence of mitotic activity and/or microvascular proliferation and the absence of necrosis in the initial diagnostic specimen or the absence of necrosis with neoplastic pseudopalisading in the posttreatment specimen. Eligible histologies included AA and anaplastic mixed oligoastrocytoma (AOA) and were based on the most recent histologic diagnosis before study enrollment. Tumors with a significant presence of the oligodendroglia component (20\% or more) were considered mixed glioma and classified as AOA. Tumors with $80 \%$ to $90 \%$ oligodendroglia component were classified as oligodendrogliomas or anaplastic oligodendroglioma. Patients had to show unequivocal evidence of tumor recurrence or progression at first relapse by gadolinium (Gd)-enhanced magnetic resonance imaging (MRI) or a contrast-enhanced computed tomography scan after failing a conventional course of radiation therapy for initial disease. The presence of assessable (measurable or nonmeasurable) enhancing residual disease documented on a baseline Gd-enhanced MRI scan was required. Multifocal disease was allowed. Only chemotherapy-naïve patients or patients previously treated with a nitrosourea in an adjuvant setting were eligible for this study. All patients were $\geq 18$ years of age with a Karnofsky performance status (KPS) $\geq 70$. Adequate laboratory values were required as follows: absolute neutrophil count $\geq 1,500 / \mu \mathrm{L}$, platelet count $\geq 100,000 / \mu \mathrm{L}$, hemoglobin greater than $10 \mathrm{~g} / \mathrm{dL}$ or 100 $\mathrm{g} / \mathrm{L}$, blood urea nitrogen and serum creatinine less than 1.5 times the upper limit of laboratory normal, total and direct serum bilirubin less than 1.5 times the upper limit of laboratory normal, AST or ALT less than three times the upper limit of laboratory normal, and alkaline phosphatase less than two times the upper limit of laboratory normal. Patients were required to have been on a nonincreasing corticosteroid dose for $\geq 72$ hours before baseline neuroimaging and study drug administration, to have a life expectancy greater than 12 weeks, and to have provided written informed consent.

\section{Treatment}

Temozolomide was administered for a maximum of 2 years or until unacceptable toxicity or tumor progression occurred. Chemotherapynaive patients received temozolomide $200 \mathrm{mg} / \mathrm{m}^{2} / \mathrm{d}$ in a fasting state for 5 consecutive days $\left(1,000 \mathrm{mg} / \mathrm{m}^{2}\right.$ per 28 -day cycle). Patients who were previously treated with any chemotherapy initially received temozolomide $150 \mathrm{mg} / \mathrm{m}^{2} / \mathrm{d}$ for 5 days $\left(750 \mathrm{mg} / \mathrm{m}^{2}\right.$ per cycle). In the absence of grade 3 or 4 hematologic toxicity, dosing for the following cycle could be increased to $200 \mathrm{mg} / \mathrm{m}^{2} / \mathrm{d}$. Repeat cycles were administered on schedule only if the absolute neutrophil count 72 hours before the first day of the next cycle was $\geq 1,500 / \mu \mathrm{L}$ and the platelet count was $\geq$ $100,000 / \mu \mathrm{L}$. Any discontinuation of treatment resulting from hospitalization, grade 4 thrombocytopenia, or low blood counts requiring administration of growth factors or transfusion was recorded as a major adverse event. Any nonhematologic or hematologic toxicity of grade 3 or 4 recorded in the previous cycle could result in dose adjustment in the following cycle at the discretion of the investigator.

Prophylactic antiemetics were permitted as needed. Neurologic stability was provided with the lowest corticosteroid dose when required. Colony-stimulating factors were permitted only for rescue from grade 4 neutropenia.

\section{Patient Evaluation}

Gd-enhanced MRI scans were performed at the principal investigators' institutions or at designated radiology facilities. Copies of all scans were centrally reviewed by a committee from Johns Hopkins University (Baltimore, MD; headed by N.Y.) The size of the enhancing tumor was defined as the product of the largest perpendicular diameters of enhancement. Nonmeasurable lesions were approximated to provide means of comparison compatible with those used for measurable lesions.

A comprehensive neurologic examination was performed at each study visit. Evaluation was based on changes in signs and symptoms from the previous examination deemed unrelated to postictal state or to such other unrelated events as infection. Relative changes were graded as definitely better $(+2)$, possibly better $(+1)$, unchanged $(0)$, possibly worse $(-1)$, or definitely worse $(-2)$.

Objective assessments of overall response were based on tumor assessments from MRI scans interpreted in the light of corticosteroid use, as suggested by Macdonald et al, ${ }^{15}$ with appropriate support from the neurologic status tests. Briefly, complete response (CR) implies disappearance of all enhancing tumor on consecutive MRI scans at least 1 month apart and no corticosteroid use except for physiologic doses, with stable or improved neurologic condition. Partial response (PR) implies a $\geq 50 \%$ reduction in contrast enhancement for all measurable lesions or a definite improvement for all nonmeasurable lesions on consecutive MRI scans at least 1 month apart and stable corticosteroid use for 7 days before each scan at the same dose administered at the time of the previous scan or at a reduced dose, with stable or improved neurologic condition. Progressive disease implies a $\geq 25 \%$ increase in 
contrast enhancement for any measurable lesions or definite worsening for any nonmeasurable lesions or any new tumor on MRI scans and stable corticosteroid use for 7 days before each scan at the same dose administered at the time of the previous scan or at an increased dose, with or without neurologic progression. Stable disease (SD) applies to all other situations.

Weekly hematologic evaluation was performed. Complete blood counts were obtained during each cycle of therapy to evaluate potential hematologic toxicity and to determine the appropriate timing and dosage for each subsequent course of therapy. Other treatmentemergent adverse events were recorded and graded using the common toxicity criteria scale.

The impact of therapy on the patients' well-being was assessed by self-administration of the validated European Organization for Research and Treatment of Cancer quality-of-life questionnaire (QLQC30), ${ }^{16,17}$ termed herein QLQ-C30 $(+3)$ because it contained three additional questions, and the recently validated malignant brain cancer module (BCM-20). ${ }^{18}$ The QLQ-C30 (+3) encompasses six HQL domains, including physical functioning, role functioning, cognitive functioning, emotional status, social functioning, and a global assessment. The BCM-20 addresses concepts of visual disorder, motor dysfunction, communication deficit, headaches, seizure, drowsiness, weakness in both legs, bladder control, uneasiness about hair loss, itchy skin, and the future. Data were collected on day 1 and at every visit throughout the study.

\section{Statistical Analysis}

PFS and overall survival were assessed by the product-limit method of Kaplan-Meier for both the ITT population and the eligible histology subgroup. The proportion of progression-free patients at 6 months was provided with a $95 \%$ confidence interval (CI) based on Kaplan-Meier estimates. Large sample CIs, based on the normal distribution, were used when the number of patients was greater than 30 and the binomial CIs were calculated when there were 30 or fewer patients.

The potential influence of baseline characteristics on PFS and overall survival was assessed using the Cox regression model. The variables included in the model were center (domestic or international), histology (AA or AOA confirmed subgroup), age, sex, prior chemotherapy, surgery at initial diagnosis, time from initial diagnosis to first relapse, time from end of radiation therapy at initial diagnosis to first relapse, and baseline KPS. Subgroup analyses were performed for both PFS and overall survival based on the prognostic variables used in the Cox model.

\section{RESULTS}

\section{Patient Characteristics}

One hundred sixty-two patients were entered onto this multicenter, single-arm, phase II trial. These patients constituted the ITT population. After central pathologic review, $111(69 \%)$ of the patients had confirmed AA or AOA. Patients with a nonAA or nonAOA histology had a variety of other histologic diagnoses (Table 1). At enrollment, patients had a median age of 42 years (range, 19 to 76 years), and $57 \%$ (93 of 162) were men. Sixty-seven percent of patients (108 of 162) had a KPS $\geq 80$. Sixty-eight percent of patients (110 of 162) had undergone surgical resection at the time of initial diagnosis, and the rest of the patients were diagnosed on the basis of stereotactic biopsy. All patients received
Table 1. Demographics and Baseline Characteristics of the Intent-to-Treat Population Receiving Temozolomide

\begin{tabular}{|c|c|c|c|}
\hline Parameter & & $\begin{array}{l}\text { No. of Patients } \\
(\mathrm{n}=162)\end{array}$ & $\%$ \\
\hline \multicolumn{4}{|l|}{ Age, years } \\
\hline Median & 42 & & \\
\hline Range & $19-76$ & & \\
\hline \multicolumn{4}{|l|}{ Sex } \\
\hline Male & & 93 & 57.4 \\
\hline Female & & 69 & 42.6 \\
\hline \multicolumn{4}{|l|}{ Karnofsky performance status } \\
\hline $90-100$ & & 75 & 46.3 \\
\hline $70-80$ & & 84 & 51.9 \\
\hline $50-60$ & & 3 & 1.8 \\
\hline \multicolumn{4}{|l|}{ Prior treatment } \\
\hline Radiation therapy & & 162 & 100 \\
\hline Chemotherapy & & 97 & 59.9 \\
\hline Surgery at initial diagnosis & & 110 & 67.9 \\
\hline Surgery at first relapse & & 30 & 18.5 \\
\hline \multicolumn{4}{|l|}{$\begin{array}{l}\text { Time to first relapse, months, } \\
\text { (range) }\end{array}$} \\
\hline $\begin{array}{l}\text { Median time from initial } \\
\text { diagnosis }\end{array}$ & $15.2(3.1-122.3)$ & & \\
\hline $\begin{array}{l}\text { M edian time from end of } \\
\text { radiation }\end{array}$ & $12.1(0.8-116.6)$ & & \\
\hline \multicolumn{4}{|l|}{ Histological diagnosis } \\
\hline $\begin{array}{c}\text { A naplastic astrocytoma, } \\
\text { eligible histology }\end{array}$ & & 97 & 60 \\
\hline $\begin{array}{l}\text { A naplastic oligoastrocy- } \\
\text { toma, eligible histology }\end{array}$ & & 14 & 9 \\
\hline Glioblastoma multiforme & & 19 & 12 \\
\hline O ligodendrogliomas & & 6 & 4 \\
\hline $\begin{array}{l}\text { A naplastic oligodendro- } \\
\text { glioma }\end{array}$ & & 6 & 4 \\
\hline Mixed astrocytoma & & 4 & 2 \\
\hline 0 ther gliomas & & 9 & 6 \\
\hline No histology & & 7 & 4 \\
\hline
\end{tabular}

radiation therapy. Nitrosourea-based chemotherapy had also been administered to $60 \%$ (97 of 162) of patients. The median time from initial diagnosis to first relapse was 15.2 months, and, at first relapse, 18\% (30 of 162) of patients had had surgical resection.

\section{Efficacy Evaluation}

All efficacy analyses were performed on the ITT population. The results of the analyses performed on the eligible histology subgroup (AA plus AOA) and the ITT population were similar. PFS at 6 months, the primary protocol end point, was $46 \%(95 \% \mathrm{Cl}, 38 \%$ to $54 \%)$ for the ITT population and $48 \%$ (95\% CI, 39\% to $58 \%$ ) for the eligible histology subgroup. Within the eligible histology group, PFS at 6 months was $49 \%$ (95\% CI, 39\% to 59\%) for patients with AA and 46\% (95\% CI, 19\% to 73\%) for patients with AOA. Median PFS was 5.4 months for patients in the ITT population and 5.5 months for eligible histology patients. Within the eligible histology group, the median 
PFS was 5.5 months for patients with AA and 5.8 months for patients with AOA. Twenty-four percent of ITT patients were progression-free at 12 months based on Kaplan-Meier estimates (Fig 1). The median overall survival was 13.6 months in the ITT population and 14.5 months in the eligible histology subgroup. Within the subgroup, median overall survival was 14.2 months for patients with AA and 14.8 months for patients with AOA. In the ITT population, the 6-month and 12-month survival rates based on KaplanMeier estimates were $75 \%$ (95\% CI, 68\% to $82 \%$ ) and $56 \%$ (95\% CI, $48 \%$ to $64 \%$ ), respectively (Fig 1). In the eligible histology subgroup, the 6-month survival rate was $78 \%$ (95\% CI, $70 \%$ to $86 \%$ ) for patients with AA and $79 \%(95 \%$ CI, $57 \%$ to $100 \%$ ) for patients with AOA.

A Cox regression analysis was performed to identify possible prognostic factors for PFS and overall survival. Only baseline KPS was shown to be a significant prognostic factor ( $P \geq .03$ ) for PFS and overall survival (Table 2). In addition, a subgroup analysis performed on each of the prognostic factors demonstrated the consistency of the results (Table 2). No factor, except baseline KPS, influenced either PFS or overall survival.

One of the most notable findings of the study was the high number of objective responses achieved with temozolomide. Based on the central reviewer's assessment of objective response, 8\% (13 of 162) of the ITT population achieved CR; 35\% (57 of 162) achieved CR or PR; and 62\% (101 of 162) achieved CR, PR, or SD (Table 3). For the 13 complete responders, the PFS range was 11 months to more than 2 years, with seven patients remaining in CR beyond 16 months. For the 44 partial responders, the median PFS was 11 months and the median overall survival was 21 months. Patients with SD had a median PFS of 4.4 months. The objective response rates achieved by the eligible histology subgroup were similar, and it is important to note that patients with AA (the majority of the eligible histology population) responded to therapy (Table 3 ). The objective response rate observed did not depend on the history of prior chemotherapy. Sixty-nine percent of patients (45 of 65) who were chemotherapy-naive achieved an objective response, whereas only $58 \%$ of patients (56 of 97) who had received prior chemotherapy achieved an objective response (Table 4).

\section{Drug Exposure}

Of the 162 patients in the ITT population, 158 received at least one cycle of temozolomide. Ninety-nine percent (156 of 158) of patients received the correct starting dose based on previous chemotherapy. The majority of patients, $93 \%$ (147 of 158), received more than one cycle of temozolomide, with a median number of five cycles. Of the patients who received more than one cycle of treatment, $88 \%$ (129 of 147) were receiving either their initial dose or a higher dose at the time of their last cycle. Dose reductions occurred in only $4 \%$ of cycles $(42$ of 1,168$)$. The primary reason for dose reductions was hematologic toxicity $(86 \%, 36$ of 42$)$. After

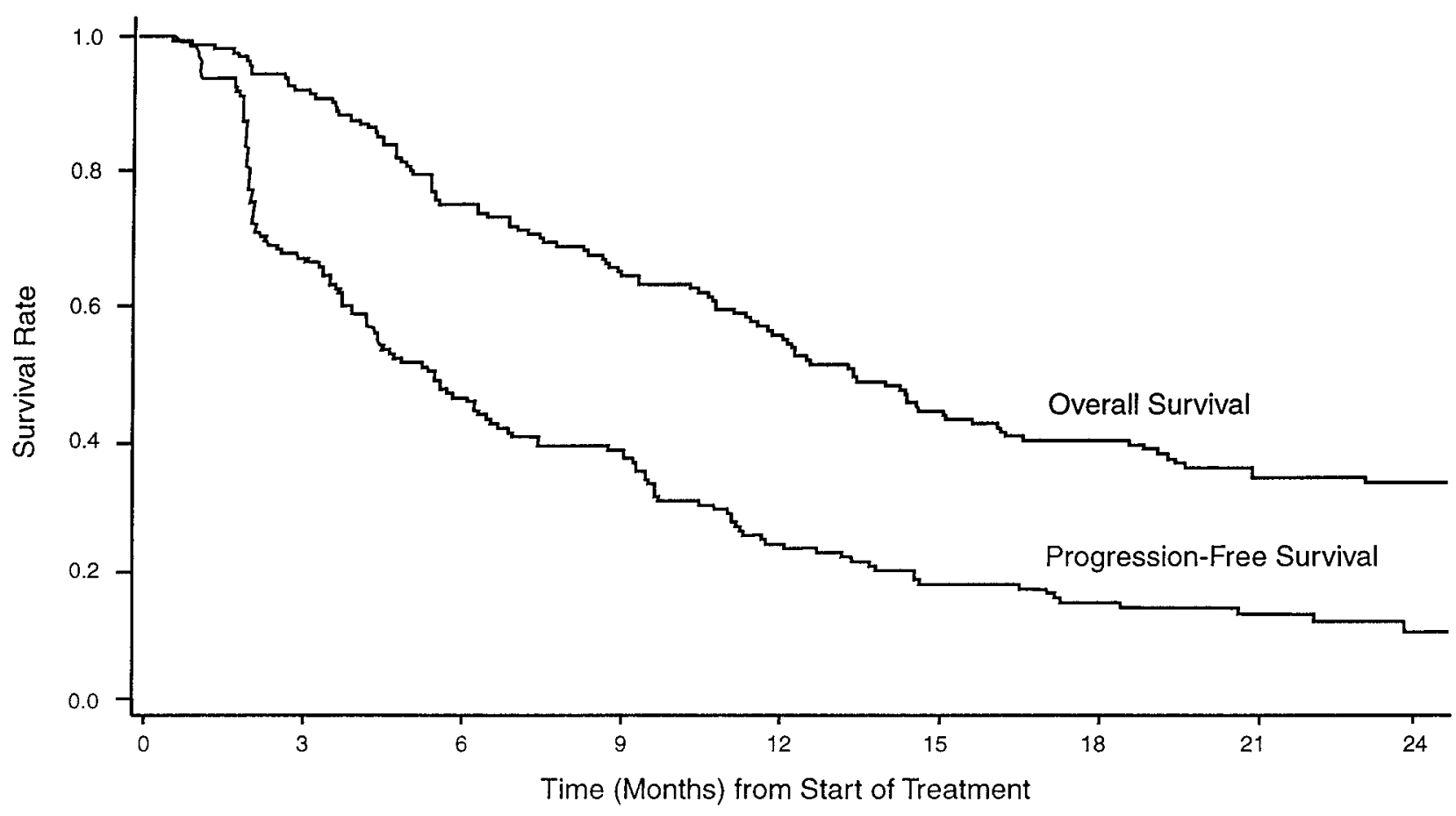

Fig 1. Kaplan-Meier estimates of PFS and overall survival in patients with malignant glioma treated with temozolomide (intent-to-treat population). 
Table 2. PFS and Overall Survival in Various Subgroups of Patients $W$ ith Malignant Astrocytoma Treated with Temozolomide

\begin{tabular}{|c|c|c|c|c|c|}
\hline \multirow[b]{2}{*}{ Variable } & \multirow{2}{*}{$\begin{array}{l}\text { No. of } \\
\text { Patients }\end{array}$} & \multirow{2}{*}{$\begin{array}{l}\text { Median } \\
\text { PFS } \\
\text { (months) }\end{array}$} & \multicolumn{2}{|c|}{$\begin{array}{l}\text { PFS at } 6 \\
\text { Months }\end{array}$} & \multirow{2}{*}{$\begin{array}{l}\text { Median } \\
\text { O verall } \\
\text { Surviva } \\
\text { (months }\end{array}$} \\
\hline & & & $(\%)$ & $95 \% \mathrm{Cl}$ & \\
\hline \multicolumn{6}{|l|}{ Population } \\
\hline Intent-to-treat & 162 & 5.4 & 46 & $39-54$ & 13.6 \\
\hline Eligible histology & 111 & 5.5 & 48 & $39-58$ & 14.5 \\
\hline \multicolumn{6}{|l|}{ Centers } \\
\hline Domestic & 92 & 5.7 & 48 & $37-58$ & 16.4 \\
\hline International & 70 & 4.4 & 44 & $32-56$ & 11.3 \\
\hline \multicolumn{6}{|l|}{ Age } \\
\hline$>45$ years & 62 & 5.8 & 49 & $36-62$ & 12.3 \\
\hline$\leq 45$ years & 100 & 5.3 & 45 & $35-55$ & 13.7 \\
\hline \multicolumn{6}{|l|}{ Sex } \\
\hline Male & 93 & 4.6 & 45 & $35-55$ & 14.6 \\
\hline Female & 69 & 5.5 & 48 & $36-60$ & 12.4 \\
\hline \multicolumn{6}{|l|}{ Baseline KPS } \\
\hline$>80$ & 75 & 6.2 & 51 & $40-62$ & 16.8 \\
\hline$\leq 80$ & 87 & 4.3 & 42 & $31-53$ & 10.8 \\
\hline \multicolumn{6}{|l|}{ Prior chemotherapy } \\
\hline Yes & 97 & 4.8 & 44 & $34-54$ & 14.6 \\
\hline No & 65 & 6.2 & 50 & $38-63$ & 11.5 \\
\hline \multicolumn{6}{|l|}{ Surgery at onset } \\
\hline Yes & 110 & 5.7 & 49 & $39-58$ & 14.6 \\
\hline No & 52 & 3.6 & 41 & $27-55$ & 11.4 \\
\hline \multicolumn{6}{|l|}{$\begin{array}{l}\text { Initial diagnostics to } \\
\text { first relapse }\end{array}$} \\
\hline$>15$ months & 82 & 6.6 & 55 & $44-65$ & 14.6 \\
\hline$\leq 15$ months & 80 & 3.5 & 38 & $27-49$ & 10.6 \\
\hline \multicolumn{6}{|l|}{$\begin{array}{l}\text { Radiation therapy to } \\
\text { first relapse }\end{array}$} \\
\hline$>11$ months & 87 & 6.3 & 52 & $41-63$ & 13.7 \\
\hline$\leq 11$ months & 75 & 3.7 & 40 & $28-51$ & 11.5 \\
\hline
\end{tabular}

cycle $1,40 \%$ of the cycles (404 of 1,010) were delayed; $39 \%$ of the delays were because of scheduling conflicts and $28 \%$ were caused by hematologic toxicity.

\section{Adverse Events}

The most common, probably treatment-related, adverse events were nausea (53\%), vomiting (42\%), headache (41\%), fatigue (34\%), and constipation (33\%). Hematologic adverse events were minimal and included thrombocytopenia $(7 \%)$, leukopenia $(2 \%)$, neutropenia (2\%), and anemia $(1 \%)$. The majority of reports of nausea and vomiting were mild to moderate in severity and were readily controlled with standard antiemetics. The most common treatmentemergent adverse events reported during all cycles of therapy are listed in Table 5. Nine patients discontinued treatment because of adverse events. Of these, only six were deemed possibly or probably related to the study drug.

\section{Quality of Life}

Seventeen of the 162 patients in the ITT population had no baseline HQL data and were excluded from the HQL analysis population. The HQL analysis included 63 patients
Table 3. Central Reviewer's Assessment of Response to Temozolomide Administration in Patients W ith Malignant Astrocytoma at First Relapse

\begin{tabular}{|c|c|c|c|c|c|c|c|c|}
\hline \multirow[b]{3}{*}{$\begin{array}{l}\text { Central Reviewer's } \\
\text { Assessment }\end{array}$} & \multirow{2}{*}{\multicolumn{2}{|c|}{$\begin{array}{l}\text { ITT Patients } \\
\text { Responding } \\
(\mathrm{N}=162)\end{array}$}} & \multicolumn{6}{|c|}{$\begin{array}{l}\text { Eligible-Histology Patients } \\
\text { Responding }(\mathrm{N}=111)\end{array}$} \\
\hline & & & \multicolumn{2}{|c|}{$\begin{array}{c}\text { AA } \\
(n=97)\end{array}$} & \multicolumn{2}{|c|}{$\begin{array}{c}A 0 A \\
(n=14)\end{array}$} & \multicolumn{2}{|c|}{ Total } \\
\hline & $\begin{array}{l}\text { No. of } \\
\text { Patients }\end{array}$ & $\%$ & $\begin{array}{l}\text { No. of } \\
\text { Patients }\end{array}$ & $\%$ & $\begin{array}{l}\text { No. of } \\
\text { Patients }\end{array}$ & $\%$ & $\begin{array}{l}\text { No. of } \\
\text { Patients }\end{array}$ & $\%$ \\
\hline$C R$ & 13 & 8 & 6 & 6 & 2 & 14 & 8 & 7 \\
\hline PR & 44 & 27 & 27 & 28 & 4 & 29 & 31 & 28 \\
\hline SD & 44 & 27 & 31 & 32 & 1 & 7 & 32 & 29 \\
\hline Total (CR + PR + SD) & 101 & 62 & 64 & 66 & 7 & 50 & 71 & 64 \\
\hline
\end{tabular}

who were progression-free at 6 months. Baseline HQL profiles, including the QLQ-C30 (+3) functioning and symptoms scores and the BCM-20 symptoms scale scores, were similar for patients who were 6-month progression-free survivors and for those whose disease had progressed by 6 months. To assess the HQL benefit of maintaining progression-free status with temozolomide, a change from baseline analysis was carried out for the 63 temozolomide patients who were progression-free survivors at 6 months and had HQL data. The mean change from baseline values for the QLQ-C30 (+3) functioning and symptoms and BCM-20 symptoms scores (Fig 2A, B, and C, respectively) showed maintenance, if not notable improvement, in the majority of HQL domain scores. This analysis highlights the clinical benefit in terms of HQL improvement associated with achieving 6-month PFS.

In addition, the HQL benefit of achieving an objective response of $\mathrm{CR}$ or $\mathrm{PR}$ or of being maintained in $\mathrm{SD}$ was evaluated. Quality-of-life improvements and responses were tabulated for these patients and compared with those who did not achieve an objective response, as assessed by the central reviewer. Among those who achieved a CR or PR or were maintained in SD, HQL responses were consistently seen across all seven domains (Fig 3A). Additionally, HQL responses in these same domains were seen in $25 \%$ to $40 \%$ of patients with a best objective response of SD. When the analysis was restricted to patients who could show improvement (ie, those with baseline functioning scores $<90$ or

\begin{tabular}{|c|c|c|c|c|}
\hline \multirow[b]{3}{*}{$\begin{array}{c}\text { Central Reviewer's } \\
\text { A ssessment }\end{array}$} & \multicolumn{4}{|c|}{ ITT Patients (N = 162) } \\
\hline & \multicolumn{2}{|c|}{$\begin{array}{l}\text { Prior Chemotherapy } \\
\qquad(\mathrm{n}=97)\end{array}$} & \multicolumn{2}{|c|}{$\begin{array}{l}\text { Chemotherapy- } N \text { aive } \\
\qquad(n=65)\end{array}$} \\
\hline & $\begin{array}{l}\text { No. of } \\
\text { Patients }\end{array}$ & $\%$ & $\begin{array}{l}\text { No. of } \\
\text { Patients }\end{array}$ & $\%$ \\
\hline$C R$ & 6 & 6 & 7 & 11 \\
\hline PR & 23 & 24 & 21 & 32 \\
\hline $\mathrm{SD}$ & 27 & 28 & 17 & 26 \\
\hline Total (CR + PR + SD) & 56 & 58 & 45 & 69 \\
\hline
\end{tabular}


Table 5. Major Adverse Events Reported in Patients $(n=158)$ During all Cycles of Temozolomide Treatment

\begin{tabular}{|c|c|c|c|c|}
\hline \multirow[b]{2}{*}{ A dverse Event } & \multicolumn{2}{|c|}{$\begin{array}{l}\text { Grade } 1 / 2 \text { Toxicity } \\
\quad(n=72)\end{array}$} & \multicolumn{2}{|c|}{$\begin{array}{l}\text { Grade } 3 / 4 \text { Toxicity } \\
\quad(n=81)\end{array}$} \\
\hline & $\begin{array}{l}\text { No. of } \\
\text { Patients }\end{array}$ & $\%$ & $\begin{array}{l}\text { No. of } \\
\text { Patients }\end{array}$ & $\%$ \\
\hline Thrombocytopenia & 1 & 1 & 10 & 6 \\
\hline N eutropenia & 0 & 0 & 3 & 2 \\
\hline Leukopenia & 0 & 0 & 3 & 2 \\
\hline A nemia & 1 & 1 & 1 & 1 \\
\hline Asthenia & 11 & 7 & 9 & 6 \\
\hline Fatigue & 47 & 30 & 7 & 5 \\
\hline Fever & 18 & 11 & 3 & 2 \\
\hline Headache & 55 & 35 & 10 & 6 \\
\hline Peripheral edema & 16 & 10 & 1 & 1 \\
\hline Convulsions & 28 & 18 & 8 & 5 \\
\hline Dizziness & 18 & 11 & 1 & 1 \\
\hline Insomnia & 16 & 10 & & \\
\hline Somnolence & 10 & 6 & 5 & 3 \\
\hline Abdominal pain & 12 & 8 & 2 & 1 \\
\hline Anorexia & 13 & 8 & 1 & 1 \\
\hline Constipation & 51 & 32 & 1 & 1 \\
\hline Diarrhea & 22 & 14 & 3 & 2 \\
\hline $\mathrm{N}$ ausea & 68 & 43 & 16 & 10 \\
\hline Vomiting & 56 & 35 & 10 & 6 \\
\hline Pruritis & 10 & 6 & 2 & 1 \\
\hline Rash & 14 & 9 & & \\
\hline Respiratory infection & 13 & 8 & & \\
\hline Viral infection & 19 & 12 & & \\
\hline
\end{tabular}

symptoms scores $>10$ ), the percentage of patients achieving HQL responses increased (Fig 3B). Ninety-two percent of patients with a CR or PR achieved an HQL response in one or more domains, and $82 \%$ had an HQL response in three or more domains. With temozolomide therapy, as many as $59 \%$ of patients with SD achieved an HQL response (Table 6).

\section{DISCUSSIO N}

The prognosis for relapsing patients with malignant astrocytoma remains poor, even when nitrosoureas are still an option. ${ }^{19}$ Recent combination therapy with carmustine (BCNU) plus interferon alfa, ${ }^{20,21}$ intra-arterial administration of BCNU with vincristine plus procarbazine, ${ }^{22}$ and other associations of $\mathrm{BCNU}$ or lomustine (CCNU) with various agents ${ }^{23-26}$ have not improved outcome significantly. However, recent results with combination PCV chemotherapy administered before or after radiation therapy have shown encouraging response rates and improved PFS and overall survival. ${ }^{27,28}$ Despite these encouraging results, in most cases median survival times rarely exceed 1 year, and the toxicity associated with the therapy is, on occasion, detrimental to the well-being of the patient, thus adding to disease burden. These considerations prompted us to design the present multicenter phase II trial to demonstrate the antitumor efficacy of temozolomide in a setting in which few drugs are effective and to assess the PFS and safety profile of this agent in a large population of patients with poor prognosis. To ensure consistency of findings among the different centers participating in the trial, both the assessment of eligible histologic diagnoses and the evaluation of response by Gd-enhanced MRI were conducted by independent central review, the former at the University of Texas M.D. Anderson Cancer Center and the latter at Johns Hopkins University. The lack of a standard, well-accepted, effective single-agent regimen made the choice of a control group difficult because rechallenge of a relapsing tumor with nitrosoureas, the only agents approved for initial therapy, is limited by the cumulative toxicity. Of the 162 patients entered onto the trial, $60 \%$ and $9 \%$ were confirmed to have AA and AOA, respectively, by histologic central review. Among this eligible histology population, 35\% of patients demonstrated a clinically meaningful objective response, with an additional $26 \%$ showing disease stabilization. This response rate compares favorably with that observed with other agents used as monotherapy, including procarbazine, with response rates $(\mathrm{CR}+\mathrm{PR})$ of $15 \%$ to $26 \%,{ }^{29,30}$ and carboplatin, with response rates of $\geq 20 \%$. $^{31,32}$ Additionally, temozolomide provided a complete response rate of $8 \%$, comparable to that observed with either procarbazine or carboplatin. ${ }^{29-32}$ PFS at 6 months, the primary end point for the study, was $46 \%$ compared with a $10 \%$ threshold of effectiveness for agents active in this population of patients. The median overall survival of 14.5 months in the eligible histology subgroup and 13.6 months in the ITT population improves hope for patients with recurrent disease. Notably, there was no difference in efficacy in patients with AA or AOA, which demonstrated that the drug is effective in the more difficult to treat and traditionally less chemosensitive AA histologic diagnosis.

These data corroborate previously reported studies with temozolomide 9 and compare favorably with the more traditional nitrosourea-based therapies. ${ }^{20-22}$ Many combination cytotoxic therapies, including $\mathrm{CCNU}, \mathrm{BCNU}$, and other agents, have produced objective response rates from $25 \%$ to $80 \%$. Many of these trials, however, included as few as six patients ${ }^{33,34}$ and rarely exceeded 45 individuals, ${ }^{35-38}$ adding to uncertainty in the evaluation of response. The median duration of response observed in these trials ranged from 3 months ${ }^{33}$ to 13 months, ${ }^{39}$ and median survival rates averaged 6 months to 7 months ${ }^{20,34,36}$ and rarely exceeded 1 year with the most recent combinations. ${ }^{21,24}$ Additionally, some of the earlier trials relied on diagnostic techniques less precise than those currently available for the evaluation of response and disease progression. The validity of MRI scanning used in this trial was also strengthened by using an independent central reviewer to preclude variability in the interpretation of the scans from the 28 centers involved in the trial. In 


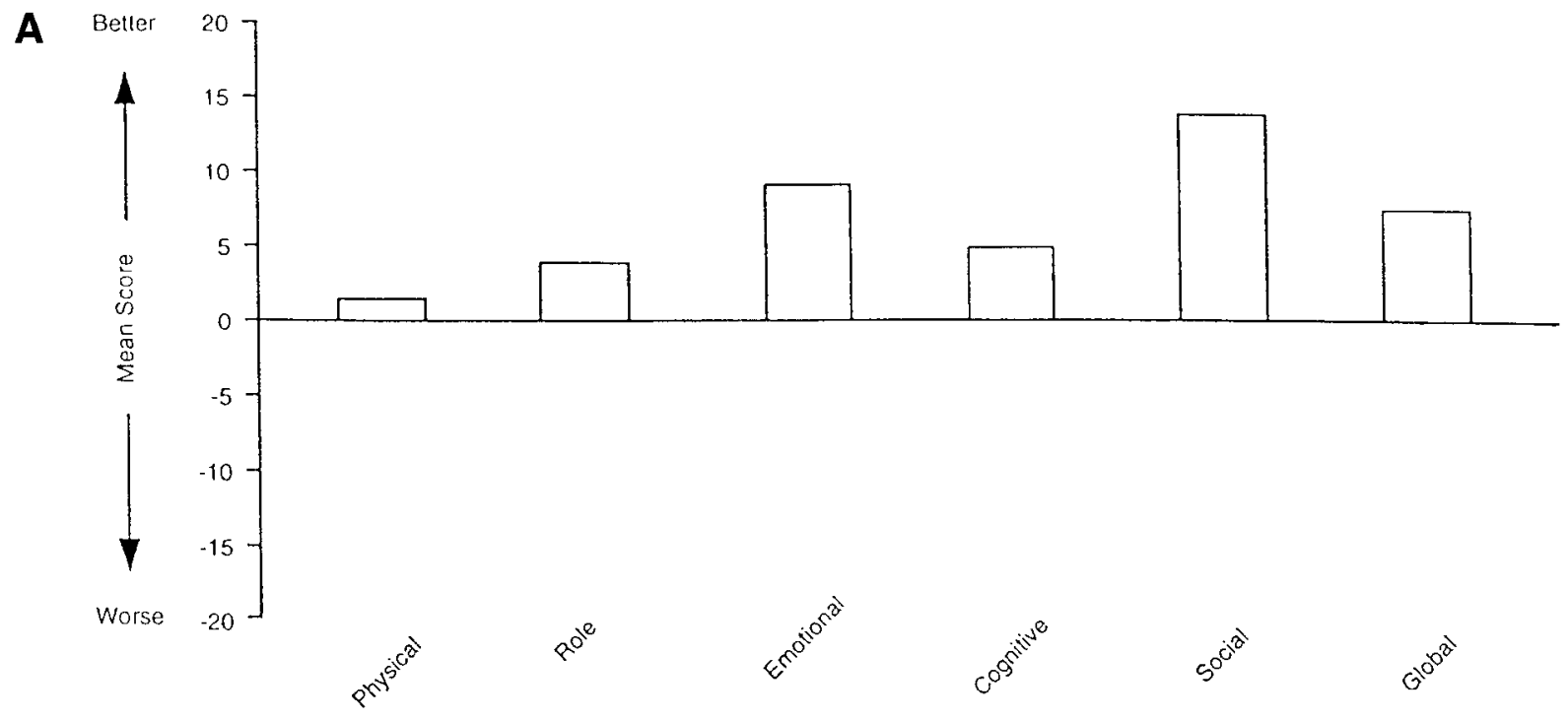

B

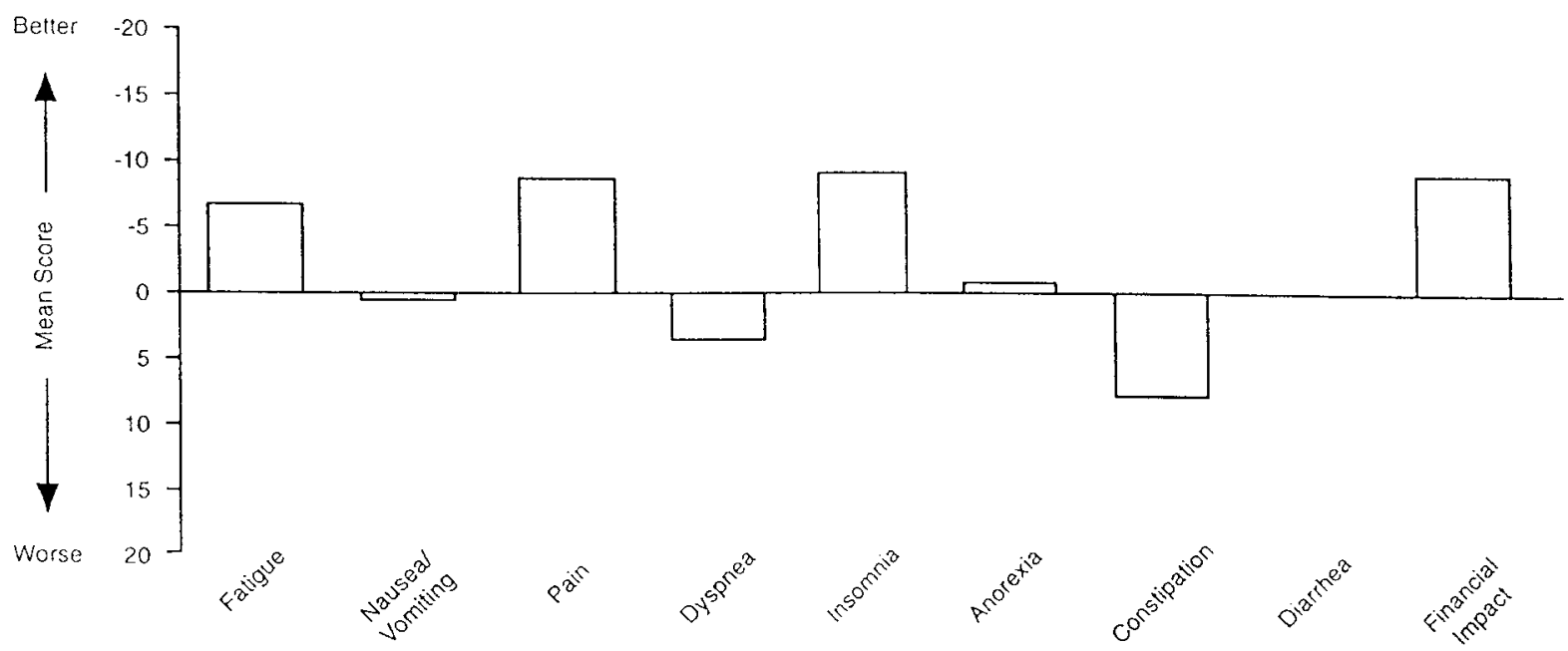

C

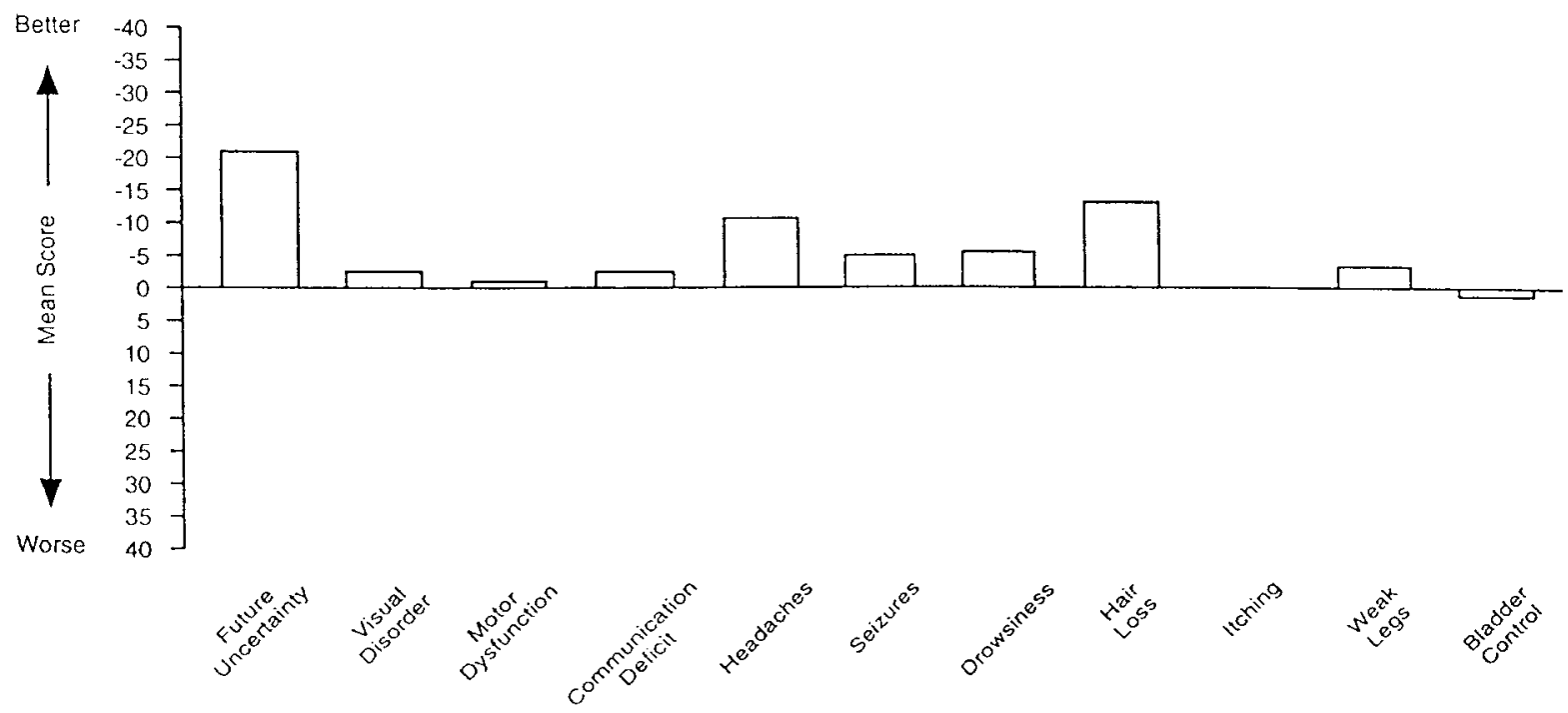

Fig 2. Mean change in Q LQ -C30 (+3) functioning scores (A) and symptoms scores (B) and BCM-20 symptoms scores (C) from baseline in progression-free survivors at 6 months.

Downloaded from jco.ascopubs.org on June 29, 2009 . For personal use only. No other uses without permission.

Copyright ( 1999 by the American Society of Clinical Oncology. All rights reserved. 


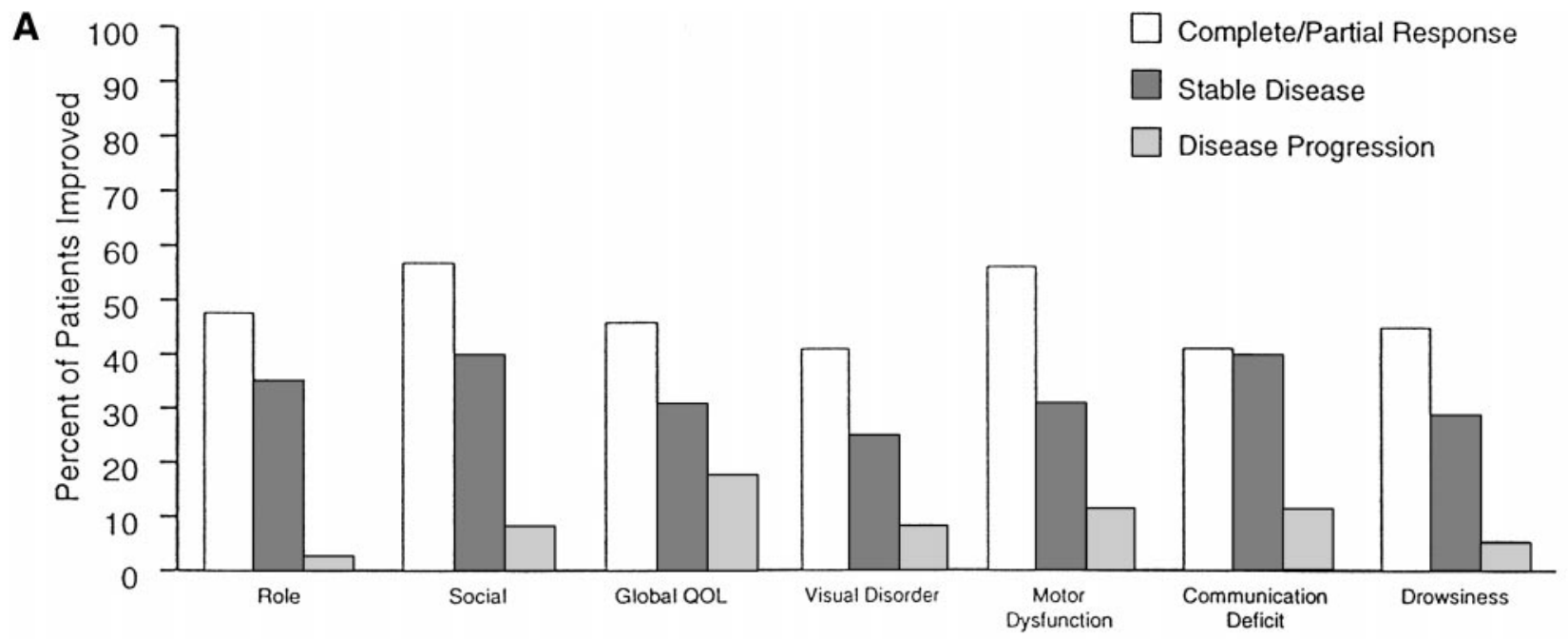

B

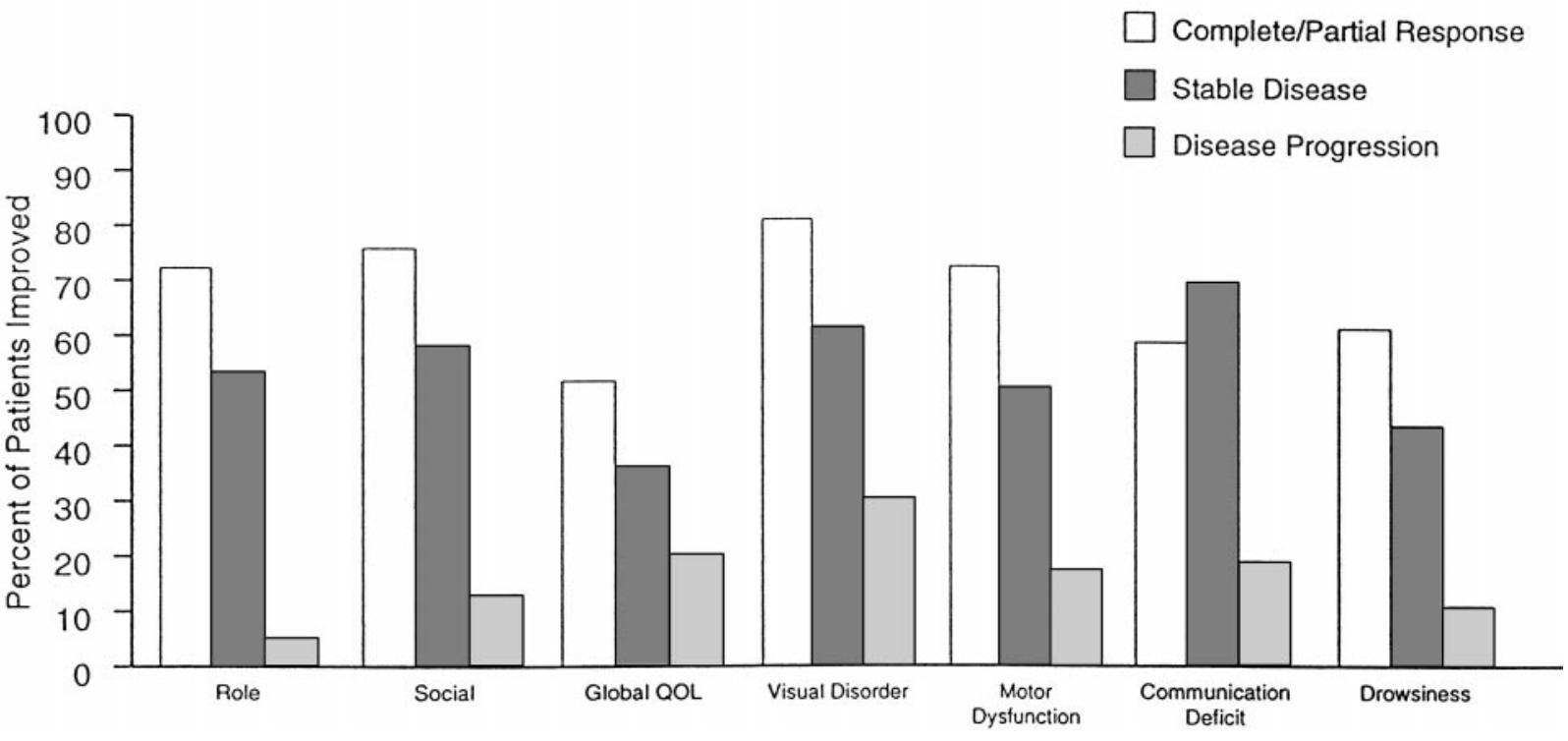

Fig 3. Proportion of patients with improved HQ L responses as a function of clinical response to temozolomide treatment; entire population (A), patients with baseline Q LQ -C30 (+3) functioning scores $<90$ or symptoms scores $>10$ (B).

addition, to minimize the possibility of an inappropriate determination of response from MRI scans because of such inherent methodologic uncertainties as extrapolation of volumetric estimates from composite scans, the determination of a response as either complete or partial required the simultaneous demonstration of neurologic improvement or symptom stabilization according to corticosteroid use and neurologic status. The subjective nature of neurologic evaluation was minimized by conducting a patient self-evaluation of HQL status at baseline and during the trial. Preliminary evaluation of these data suggests that responses (as determined by MRI and corticosteroid use criteria) to therapy and maintenance of progression-free status were both associated with an improved HQL; the majority of responders did not use corticosteroids, and few patients with an improved HQL required an increase in corticosteroid use (in preparation). These data strengthen the correlation of a response, as determined by MRI scans, with neurologic status and overall well-being as experienced by the patients.

Subanalyses performed to determine the existence of prognostic factors in the patient population under evaluation revealed that baseline KPS was the only prognostic factor that correlated meaningfully with median survival. Patient age had little relationship to either median PFS or overall survival. Although many other studies have shown that chemotherapy seems to provide better overall survival 


\begin{tabular}{|c|c|c|c|c|c|c|c|c|c|c|c|}
\hline \multirow[b]{2}{*}{$\begin{array}{l}\text { Clinical } \\
\text { Response }\end{array}$} & \multirow[b]{2}{*}{$\begin{array}{l}\text { No. of } \\
\text { Patients }\end{array}$} & \multicolumn{2}{|c|}{$\begin{array}{c}\text { No } \\
\text { Improvement }\end{array}$} & \multicolumn{2}{|c|}{$\begin{array}{l}\geq 1 \text { Improved } \\
\text { Domains }\end{array}$} & \multicolumn{2}{|c|}{$\begin{array}{c}\geq 2 \text { Improved } \\
\text { Domains }\end{array}$} & \multicolumn{2}{|c|}{$\begin{array}{c}\geq 3 \text { Improved } \\
\text { Domains }\end{array}$} & \multicolumn{2}{|c|}{$\begin{array}{c}\geq 4 \text { Improved } \\
\text { Domains }\end{array}$} \\
\hline & & $\begin{array}{l}\text { No. of } \\
\text { Patients }\end{array}$ & $\%$ & $\begin{array}{l}\text { No. of } \\
\text { Patients }\end{array}$ & $\%$ & $\begin{array}{l}\text { No. of } \\
\text { Patients }\end{array}$ & $\%$ & $\begin{array}{l}\text { No. of } \\
\text { Patients }\end{array}$ & $\%$ & $\begin{array}{l}\text { No. of } \\
\text { Patients }\end{array}$ & $\%$ \\
\hline$C R+P R$ & 51 & 4 & 8 & 47 & 92 & 46 & 90 & 42 & 82 & 35 & 69 \\
\hline $\mathrm{SD}$ & 46 & 10 & 22 & 36 & 78 & 32 & 70 & 27 & 59 & 19 & 41 \\
\hline PD & 35 & 21 & 60 & 14 & 40 & 12 & 34 & 7 & 20 & 2 & 6 \\
\hline Total & 132 & 35 & 27 & 97 & 73 & 90 & 68 & 76 & 58 & 56 & 42 \\
\hline
\end{tabular}

rates in patients younger than 60 years of age compared with older patients, the lack of age effect in this study was not entirely unexpected because the majority of patients were younger than usual. This situation caused the selection of an age split at 45 years of age to provide a meaningful analysis.

Myelosuppression, a well-documented side effect of therapy with alkylating agents, was noncumulative with temozolomide and typically resolved with a one-dose level reduction. Consequently, therapy could be administered continuously, and although the median number of adminis- tered cycles was five, 36 patients $(23 \%)$ received 12 cycles and one patient received as many as 22 cycles. Similarly, the majority of reported side effects were mild to moderate in severity. Nausea and vomiting, the most frequently reported adverse events, were also mild to moderate and could be readily controlled with the administration of standard antiemetics. The noncumulative toxicity and favorable adverse events profile of temozolomide make this agent a logical choice against recurrent malignant astrocytomas and suggest that, unlike nitrosoureas, it could be used effectively at relapse.

\section{A PPEN DIX}

Participants in the Temodal Brain Tumor Group Study

The following investigators participated in the study: M. Brada, The Royal Marsden Hospital, Sutton, Surrey, United Kingdom; M. Findlay, Royal Prince Alfred Hospital, Camperdown, Australia; J. Villemure, Institut Neurologique de Montreal, Quebec, Canada; D. Stewart, Ottawa Regional Cancer Center, Ontario, Canada; D.R. MacDonald, The London Regional Cancer Center, Ontario, Canada; H.S. Poulsen, Rigshospitalet, Copenhagen, Denmark; O. Chinot, Hopital de la Timone, Marseille, France; J.-Y. Delattre, Hopital Pitie-Salpetriere, Paris, France; E. Bouffet, Centre Regional Leon Berard, Lyon, France; B. Zonnenberg, University Hospital Utrecht, Utrecht, The Netherland; M. Santos Ortega, Sanatorio San Francisco de Asis, Madrid, Spain; F. Lejeune, Kantonsspitals Basel, Basel, Switzerland; C. Zielinski, University Clinic Vienna, Vienna, Austria; L. Davila Maldonado, Hospital Angeles, Mexico City, Mexico; V. Levin, W.K.A. Yung, University of Texas M.D. Anderson Cancer Center, Houston, TX; M. Prados, University of California, San Francisco, San Francisco, CA; H. Friedman, Duke University Medical Center, Durham, NC; W. Shapiro, Barrow Neurological Institute, Phoenix, AZ; R.E. Albright, Barrett Cancer Center, Cincinnati, OH; M. Glantz, Memorial Hospital of Rhode Island, Pawtucket, RI; K. Fink, University of Texas, Southwestern Medical School, Dallas, TX; H. Greenberg, University of Michigan Medical Center, Ann Arbor, MI; N.A. Vick, N. Paleologos, Evanston Hospital, Evanston, IL; R.G. Selker, West Penn Hospital, Pittsburgh, PA; S. Rosenfeld, University of Alabama at Birmingham, Birmingham, AL; J. Olson, The Emory Clinic, Atlanta, GA; A. Spence, University of Washington, Seattle, WA; P. Phillips, University of Pennsylvania Medical Center, Hospital of the University of Pennsylvania, Philadelphia, PA; L. Dirix, Universitair Ziekenhuis Antwerpen, Edegem, Belgium; R. Engenhart-Cabillic, F.K. Albert, Klinikum der Ruprecht-Karls Universität Heidelberg, Heidelberg, Germany; B. Marques, D. Salgado, Instituto Portugues de Oncologia, Lisbon, Portugal.

\section{REFEREN CES}

1. Burger PC, Vogel FS, Green SB, et al: Glioblastoma multiforme and anaplastic astrocytoma: Pathologic criteria and prognostic implications. Cancer 56:1106-1111, 1985

2. Nelson JS, Tsukada Y, Schoenfeld D, et al: Necrosis as a prognostic criterion in malignant supratentorial, astrocytic gliomas. Cancer 52:550-554, 1983

3. Levin VA, Silver P, Hannigan J, et al: Superiority of post-radiotherapy adjuvant chemotherapy with $\mathrm{CCNU}$, procarbazine, and vincristine (PCV) over BCNU for anaplastic gliomas: NCOG 6G61 final report. Int J Radiat Oncol Biol Phys 18:321-324, 1990
4. Rodriguez LA, Levin VA: Does chemotherapy benefit the patient with a central nervous system glioma? Oncology 1:29-36, 1987

5. Newlands ES, Blackledge GR, Slack JA, et al: Phase I trial of temozolomide (CCRG 81045:M\&B 39831:NSC 362856). Br J Cancer 65:287-291, 1992

6. O'Reilly SM, Newlands ES, Glaser MG, et al: Temozolomide: A new cytotoxic agent with promising activity against gliomas. Proc Am Soc Clin Oncol 12:176a, 1993 (abstr 499)

7. O'Reilly SM, Newlands ES, Glaser MG, et al: Temozolomide: A new oral cytotoxic chemotherapeutic agent with promising activity against primary brain tumours. Eur J Cancer 29:940-942, 1993 
8. Levin V, Yung A, Prados M, et al: Phase II study of Temodal ${ }^{\circledR}$ (temozolomide) at first relapse in anaplastic astrocytoma (AA) patients. Proc Am Soc Clin Oncol 16:384a, 1997 (abstr 1370)

9. Newlands ES, O'Reilly SM, Glaser MG, et al: The Charing Cross Hospital experience with temozolomide in patients with gliomas. Eur J Cancer 32:2236-2241, 1996

10. Plowman J, Waud WR, Koutsoukos AD, et al: Preclinical antitumor activity of temozolomide in mice: Efficacy against human brain tumor xenografts and synergism with 1,3-bis(2-chloroethyl)-1nitrosourea. Cancer Res 54:3793-3799, 1994

11. Brada M, Moore S, Judson I, et al: A phase I study of SCH 52365 (temozolomide) in adult patients with advanced cancer. Proc Am Soc Clin Oncol 14:470a, 1995 (abstr A1521)

12. Clark AS, Deans B, Stevens MF, et al: Antitumor imidazotetrazines: 32. Synthesis of novel imidazotetrazinones and related bicyclic heterocycles to probe the mode of action of the antitumor drug temozolomide. J Med Chem 38:1493-1504, 1995

13. Tisdale MJ: Antitumor imidazotetrazines: XV. Role of guanine 06 alkylation in the mechanism of cytotoxicity of imidazotetrazinones. Biochem Pharmacol 36:457-462, 1987

14. Meikle SR, Matthews JC, Brock CS, et al: Pharmacokinetic assessment of novel anti-cancer drugs using spectral analysis and positron emission tomography: A feasibility study. Cancer Chemother Pharmacol 42:183-193, 1998

15. Macdonald DR, Cascino TL, Schold SC Jr, et al: Response criteria for phase II studies of supratentorial malignant glioma. J Clin Oncol 8:1277-1280, 1990

16. Aaronson NK, Ahmedzai S, Bergman B, et al: The European Organization for Research and Treatment of Cancer QLQ-C30: A quality-of-life instrument for use in international clinical trials in oncology. J Natl Cancer Inst 85:365-376, 1993

17. Groenvold M, Klee MC, Sprangers MA, et al: Validation of the EORTC QLQ-C30 quality of life questionnaire through combined qualitative and quantitative assessment of patient-observer agreement. J Clin Epidemiol 50:441-450, 1997

18. Osoba D, Aaronson NK, Muller M, et al: Effect of neurological dysfunction on health-related quality of life in patients with high-grade glioma. J Neurooncol 34:263-278, 1997

19. Berger MS, Leibel SA, Bruner JM, et al: Primary central nervous system tumors of the supratentorial compartment, in Levin VA (ed): Cancer in the Nervous System. New York, NY, Churchill Livingstone, 1995

20. Brandes AA, Scelzi E, Zampieri P, et al: Phase II trial with BCNU plus alpha-interferon in patients with recurrent high-grade gliomas. Am J Clin Oncol 20:364-367, 1997

21. Buckner JC, Brown LD, Kugler JW, et al: Phase II evaluation of recombinant interferon alpha and BCNU in recurrent glioma. J Neurosurg 82:430-435, 1995

22. Watne K, Hannisdal E, Nome O, et al: Combined intra-arterial and systemic chemotherapy for recurrent malignant brain tumors. Neurosurgery 30:223-227, 1992

23. Hildebrand J, De Witte O, Sahmoud T: Response of recurrent glioblastoma and anaplastic astrocytoma to dibromodulcitol,
BCNU and procarbazine: A phase II study. J Neurooncol 37:155-160, 1998

24. Hochberg F, Prados M, Russell C, et al: Treatment of recurrent malignant glioma with BCNU-fluosol and oxygen inhalation: A phase I-II study. J Neurooncol 32:45-55, 1997

25. Yung WK, Harris MI, Bruner JM, et al: Intravenous BCNU and AZQ in patients with recurrent malignant gliomas. J Neurooncol 7:237-240, 1989

26. Prados M, Rodriguez L, Chamberlain M, et al: Treatment of recurrent gliomas with 1,3-bis(2-chloroethyl)-1-nitrosourea and alphadifluoromethylornithine. Neurosurgery 24:806-809, 1989

27. Glass J, Hochberg FH, Gruber ML, et al: The treatment of odendrogliomas and mixed oligodendroglioma-astrocytomas with PCV chemotherapy. J Neurosurg 76:741-745, 1992

28. Kim L, Hochberg FH, Thornton AF, et al: Procarbazine, lomustine, and vincristine (PCV) chemotherapy for grade III and grade IV oligoastrocytomas. J Neurosurg 85:602-607, 1996

29. Rodriguez LA, Prados M, Silver P, et al: Reevaluation of procarbazine for the treatment of recurrent malignant central nervous system tumors. Cancer 64:2420-2423, 1989

30. Newton HB, Junck L, Bromberg J, et al: Procarbazine chemotherapy in the treatment of recurrent malignant astrocytomas after radiation and nitrosourea failure. Neurology 40:1743-1746, 1990

31. Yung WK, Mechtler L, Gleason MJ: Intravenous carboplatin for recurrent malignant glioma: A phase II study. J Clin Oncol 9:860-864, 1991

32. Warnick RE, Prados MD, Mack EE, et al: A phase II study of intravenous carboplatin for the treatment of recurrent gliomas. J Neurooncol 19:69-74, 1994

33. Taylor SG, Nelson L, Baxter D, et al: Treatment of grade III and IV astrocytoma with dimethyl triazeno imidazole carboxamide (DTIC, NSC-45388) alone and in combination with CCNU (NSC-79037) or methyl CCNU (MeCCNU, NSC-95441). Cancer 36:1269-1276, 1975

34. Zander E, de Tribolet N, Wagenknecht L: Combined chemotherapy with VM 26 and BCNU for recurrent malignant gliomas after operation and irradiation. Acta Neurochir 42:97-101, 1978

35. Levin VA, Crafts DC, Wilson CB, et al: BCNU (NSC-409962) and procarbazine (NSC-77213) treatment for malignant brain tumors. Cancer Treat Rep 60:243-249, 1976

36. Pouillart P, Mathe G, Thy TH, et al: Treatment of malignant glioms and brain metastases in adults with a combination of adriamycin, VM 26 and CCNU: Results of a phase II trial. Cancer 38:1909-1916, 1976

37. Levin VA, Hoffman WF, Pischer TL, et al: BCNU-5-fluorouracil combination therapy for recurrent malignant brain tumors. Cancer Treat Rep 62:2071-2076, 1978

38. Levin VA, Prados MD: Treatment of recurrent gliomas and metastatic brain tumors with a polydrug protocol designed to combat nitrosourea resistance. J Clin Oncol 10:766-771, 1992

39. Seiler RW, Vassella F, Markwalder H: Combination chemotherapy with VM 26 and CCNU in primary malignant brain tumors. Surg Neurol 11:237-242, 1979 


\section{CORRESPONDENCE}

\section{BRCA1/BRCA2 in Breast-Conserving Therapy}

To the Editor: The Editorial by Hellman in the October 1999 issue $^{1}$ critiques our article regarding the frequency of BRCA1/2 mutations in a cohort of conservatively treated locally recurrent breast cancer patients. The thrust of the criticism seems to be in the case-control design of the study. Although case-control studies do have potential problems with respect to selection biases, it is a scientifically valid and time-tested methodology. Case-control designs have formed the basis of clinical studies in all aspects of medicine. In simple terms, one is evaluating whether individuals with a specified outcome (in our study, conservatively treated patients with ipsilateral breast tumor relapse [IBTR]), in contrast to matched individuals without that outcome (in our study, conservatively treated patients without IBTR), differ in regard to the parameter to be evaluated (in our study, BRCA1/2 mutations). While we acknowledge relatively small numbers in our study, the fundamental design of the study is sound, matching was done as closely as possible, and the study was done in a prospective fashion with a specific hypothesis. Our initial hypothesis was that there would be no difference in the frequency of germline BRCA1/2 mutations between the cases and controls, but we found, with a probability of $P<.03$, that the null hypothesis was void. Although we concur with Hellman that a more desirable study would clearly have been to test all individuals in the database to assess the actuarial risk of IBTR as a function of $B R C A 1 / 2$ status, the logistics and funding for such an undertaking (given an estimated cost of $\$ 2,000 /$ test) were not feasible at that time. One must acknowledge the tremendous amount of effort, funding, and extensive participation of patients as well as investigators that is required to conduct these studies. As we stated in our Discussion, however, we have since initiated a study, performing complete sequencing of the BRCA1/2 gene in a larger cohort of patients under age 40 , that will yield the actuarial risk of IBTR as a function of $B R C A 1 / 2$ status. Until results from this and other studies are available, our report in the Journal of Clinical Oncology presents the first available data to suggest a higher frequency than expected of germline BRCA1/2 mutations in a cohort of conservatively treated patients with locally recurrent breast cancer. The potential corollary to this finding is that patients with BRCA1/2 mutations may be at higher risk for late IBTR.

A critical observation from our report is that the median time to IBTR in patients with $B R C A 1 / 2$ mutations exceeded 7 years. Our long median follow-up time of over 14 years was necessary to observe these late local relapses, and the clinical-pathologic assessment of the primary tumors and relapses strongly suggests that these events represent second primary tumors and not true recurrences. It is therefore not surprising that studies with follow-up periods of less than 8 years will fail to make these observations. Since all residual breast tissue harbors the same mutations, the development of late second primary tumors in the residual tissue in these patients does in fact make biologic sense. Although treatment decisions should not be made based solely on the data presented in our article, we believe the information presented provides valuable insights into the natural history of IBTR in patients with BRCA1/2 mutations. We clearly state in our Discussion that the clinical implications of our study are complicated and must take into account the limitations of the current study. We acknowledge that larger confirmatory studies are warranted, and as noted above, such studies are currently being conducted by ourselves as well as others.

Bruce C. Turner Thomas Jefferson University Hospital Philadelphia, PA Peter M. Glazer Bruce G. Haffty Yale University School of Medicine New Haven, $C T$

\section{REFERENCES}

1. Hellman S: The key and the lamppost. J Clin Oncol 17:3007-3008, 1999

2. Turner BC, Harrold E, Matloff E, et al: BRCA1/BRCA2 germline mutations in locally recurrent breast cancer patients after lumpectomy and radiation therapy: Implications for breast-conserving management in patients with BRCA1/BRCA2 mutations. J Clin Oncol 17:3017-3024, 1999

In Reply: The authors misinterpret my concerns. I have no quarrel with case-control studies in general, but rather that the question as to whether there is a greater likelihood of recurrence in patients with BRCA1/2 mutations is not addressed by this experiment. This experiment asks the obverse question: In a series of recurrent patients, do these mutations occur more frequently? Although an increase in BRCA1/2 mutations was found, this observation is consistent with a number of alternative explanations (see Editorial) that are indistinguishable in design.

\author{
Samuel Hellman \\ University of Chicago \\ Chicago, IL
}

\section{Tamoxifen and Sexuality: Let's Listen to the Data Speak}

To the Editor: Whether ${ }^{1}$ or not ${ }^{2}$ tamoxifen or another agent is adopted as a breast cancer prevention agent depends on an accurate assessment of the risk-to-benefit ratio. The article by Mortimer et $\mathrm{al}^{3}$ brings us a short-term, retrospective review of what effects tamoxifen has on the sexual functions of women with breast cancer who have been treated with the drug as well as what estrogenic effects tamoxifen has on the vaginal mucosa.

In the Introduction, the authors start out with a reasonable hypothesis. Specifically, they note that one theory was that tamoxifen might have an estrogen agonist effect on vaginal mucosa and thereby increase lubrication and improve sexual function. What was the effect of tamoxifen on the vaginal mucosa of patients? The authors state: "The women in whom estrogen effect was seen tended to be older. The median age for patients with estrogen effect was 54.5 years, compared with 49 years for patients without estrogen effect $(P=.054)$." Unfortunately, $54 \%$ of women responding to a questionnaire complained of pain, burning, or discomfort during sexual intercourse. Even worse, the presence of an estrogen effect was associated with negative reactions 
during intercourse $(P=.02)$ and vaginal dryness or tightness $(P=.046)$. The tamoxifen did have an estrogen effect on the mucosa of older patients, but they were not advantaged.

In their Summary, Mortimer et $\mathrm{al}^{3}$ report that "In our trial, we found an inverse correlation between the age and estrogen effect on the vagina, although this did not achieve statistical significance $(P=.054)$."

Assuming that the apparent contradiction is a typographical error, perhaps instead of concluding that their study "raises the possibility that tamoxifen may have estrogen agonist effects on the vagina of postmenopausal women and antagonist effects on younger women," we should let the data speak. First, with $91 \%$ of either the 57 women completing the survey or the 41 patients in partnered relationships being postmenopausal, multiplication leads us to suspect that there are only four to five patients in the premenopausal group. There may well be insufficient data for meaningful subgroup analysis on the vaginal mucosa of premenopausal women who have taken tamoxifen.

The Introduction states that findings on vaginal smears were then correlated with symptoms of sexual dysfunction. As stated, the presence of an estrogen effect was significantly associated with negative reactions during sex and either vaginal dryness or tightness.

In their Discussion, the authors appropriately note the association of tamoxifen with dyspareunia suggested by the data. The authors might have concluded that in the postmenopausal group, although tamoxifen may have increased the karyopyknotic index, qualitatively at least, tamoxifen did not seem to improve vaginal lubrication, as manifested by the negative reactions during sex or either vaginal dryness or tightness. Apparently, the mucosal maturation index does not correlate with improved sexual function.

I can agree with the authors that further prospective studies are warranted, but after stating our hypothesis, let's be careful. The most important end point was sexual function, and the fact that the mucosa evidenced estrogenic changes did not change the fact that those patients whose mucosa was affected by tamoxifen suffered.

\section{Jonathan J. Beitler Montefiore Medical Center Bronx, NY}

\section{REFERENCES}

1. Fisher B, Costantino JP, Wickerham DL, et al: Tamoxifen for prevention of breast cancer: Report of the National Surgical Adjuvant Breast and Bowel Project P-1 study. J Natl Cancer Inst 90:1371-1388, 1998

2. Veronesi U, Maisonneuve P, Costa A, et al: Prevention of breast cancer with tamoxifen: Preliminary findings from the Italian randomised trial among hysterectomised women-Italian Tamoxifen Prevention Study. Lancet 352:93-97, 1998

3. Mortimer JE, Boucher L, Baty J, et al: Effect of tamoxifen on sexual functioning in patients with breast cancer. J Clin Oncol 17:1488-1492, 1999

In Reply: We agree with Dr Beitler. Our data "suggest" that tamoxifen is less estrogenic on a vaginal mucosa of younger women than older women. However, we can conclude that women on tamoxifen experienced dyspareunia despite this estrogen effect. The literature supports the role of estrogen in improving symptoms of atrophic vaginitis ${ }^{1,2}$ but does not address dyspareunia per se.

On the other hand, the recently published results on health-related quality of life in NSABP $\mathrm{P}^{3}$ also suggest age-related effects of tamoxifen on the vaginal mucosa. The relative risk of vaginal discharge was 2.31 in women $\geq 60$ years old, 1.64 in women 50 to 59 years old, and 1.35 in women 35 to 49 years old. Additionally, women assigned to tamoxifen experienced a significant decrease in sexual interest, sexual arousal, and ability to have orgasm.

In response to publication of our study, I have received many inquiries from breast cancer survivors about sexual functioning. Sexuality is an important component of quality of life. Unquestionably, well-designed prospective studies of breast cancer patients are needed.

$$
\begin{array}{r}
\text { Joanne E. Mortimer } \\
\text { Diane Knapp } \\
\text { Washington University School of Medicine } \\
\text { St Louis, MO }
\end{array}
$$

\section{REFERENCES}

1. Leiblum S, Bachmann G, Kemmann E, et al: Vaginal atrophy in the postmenopausal woman. JAMA 249:2195-2198, 1983

2. Semmens JP, Wagner G: Estrogen deprivation and vaginal function in postmenopausal women. JAMA 248:445-448, 1982

3. Day R, Ganz PA, Costantino JP, et al: Health-related quality of life and tamoxifen in breast cancer prevention: A report from the National Surgical Adjuvant Breast and Bowel Project P-1 study. J Clin Oncol 17:2659-2669, 1999

\section{Fluorescence In Situ Hybridization Versus Immunohistochemistry: Importance of Clinical Outcome}

To the Editor: The two Rapid Publication articles by Jacobs et al, published in the July 1999 issue of the Journal of Clinical Oncology, ${ }^{1,2}$ on methods for assessment of HER-2 status highlight several serious concerns for the medical community and patients with breast cancer.

1. Can the method of immunohistochemistry (IHC) be reliably used for HER-2 status assessment in light of the ever-changing modifications of the subjective reading and interpretation process?

2. There are two different sources for discordant specimen results based on IHC versus fluorescence in situ hybridization (FISH). (a) One or both of the methods may generate false-positive or false-negative results. (b) The discordant specimens may reflect the fact that two fundamentally different aspects of cellular function and biology are measured.

3. These studies by Jacobs et al fail to shed light on resolving this dilemma. Comparing different methods of biochemical measurements to each other isolated from clinical outcome data does not seem like a very productive path to resolving this dilemma. Is it possible that the discordant specimens mean the tumors are different biochemically and this difference may be as important to the therapeutic decision-making process as the nondiscordant specimens? Specifically, do the patients in the four groups (IHC-positive/FISH-positive, IHC-positive/FISHnegative, IHC-negative/FISH-positive, IHC-negative/FISH-negative) behave in a similar or different way in response to treatment or prognosis?

4. The authors calculate cost estimates based on cost of materials. First, from the patient perspective, cost is not terribly relevant if an incorrect therapy decision is made based on inaccurate results. Second, the overall health care perspective needs to include the financial consequences of both the false-positive and false-negative results. It would be a valuable exercise to have health care economists assess these contributions to cost before deciding whether one technology or another is cost effective. 
These questions and uncertainties lead me to a couple of basic conclusions. We know that IHC is a subjective technology with laboratory differences in approach to analysis and interpretation. Furthermore, there is insufficient information to make a decision as to whether IHC or FISH technology is better for the management of patients with breast cancer. All specimens should probably be tested with both approaches until there is sufficient information to make an intelligent decision as to the best path.

Clearly, there needs to be a nationally organized effort to design and conduct a series of informative studies comparing the technologies so the best decisions can be made for women with breast cancer. If we leave it to individual investigators with a few hundred patients in their cohort, it will be a long time before the story becomes clear, and women will likely suffer from an unreliable decision-making process.

\section{Steven Seelig \\ Vysis, Inc \\ Downer's Grove, IL}

\section{REFERENCES}

1. Jacobs TW, Gown AM, Yaziji H, et al: Comparison of fluorescence in situ hybridization and immunohistochemistry for the evaluation of HER-2/neu in breast cancer. J Clin Oncol 17:1974-1982, 1999

2. Jacobs TW, Gown AM, Yaziji H, et al: Specificity of HercepTest in Determining HER-2/neu status of breast cancers using the United States Food and Drug Administration-approved scoring system. J Clin Oncol 17:1983-1987, 1999

In Reply: We read with interest the letter o Dr Seelig and we are pleased to have the opportunity to respond to his comments. We agree completely that there remain a number of unresolved issues regarding the most appropriate assay method for determination of the HER-2/neu status in breast cancer specimens, and our articles have highlighted some of these concerns. ${ }^{1,2} \mathrm{We}$ also agree with Seelig's comment that at the present time, "there is insufficient information to make a decision as to whether IHC or FISH technology is better for the management of patients with breast cancer." This is related to the fact that in all of the available clinical outcome studies relating HER-2/neu status to therapeutic response, IHC was used. To our knowledge, there are as yet no published data relating $H E R-2 / n e u$ gene amplification as detected by FISH to response to either tamoxifen, cytotoxic therapy, or trastuzumab, although studies are currently underway to address this. Although neither our studies nor other studies published to date have completely resolved the methodologic problems with HER-2/neu analysis, we think that they have provided some data that will ultimately be of value in that regard.

Seelig further suggests that to circumvent the uncertainty with regard to which assay is better, "[a]ll specimens should probably be tested with both approaches until there is sufficient information to make an intelligent decision as to the best path." We do not agree with this recommendation (outside of the setting of a research study) for a variety of reasons. First, a number of studies, including one of ours, ${ }^{1}$ have shown a high level of concordance between the two assay methods when appropriate attention is paid to technical and interpretive details of the assays. Second, although most pathology laboratories are capable of routinely performing IHC, the routine use of FISH is beyond the scope of many pathology departments. Third, the simultaneous use of both assays will result in a number of cases with discordant findings, and this will in turn create confusion with regard to clinical decision making. Fourth, Seelig notes that "IHC is a subjective technology with laboratory differences in approach to analysis and interpretation." In fact, all pathology laboratory tests, from routine hematoxylin and eosin stains to polymerase chain reaction, are subject to differences in approach to analysis and interpretation. The critical question is the degree of variation. In fact, in a recent study in which the same 100 consecutive invasive breast cancers were subjected to HER-2/neu IHC staining and interpretation in two different laboratories, there was complete concordance with regard to categorization of HER-2/neu status in $97 \%$ of the cases. ${ }^{3}$ In contrast, there are no published studies to our knowledge addressing these issues with regard to FISH. We believe that it is ill-advised to consider FISH any more accurate or reproducible than IHC until data are available to support this view. It should also be noted that Seelig's comments regarding IHC should be viewed as somewhat less than objective, since he is the Chief Medical Officer and Vice President for Research and Development for Vysis, Inc, Downer's Grove, IL, a company that is aggressively marketing a FISH probe for $H E R-2 / n e u$ and touting it in their advertisements as "the most accurate and reliable means of assessing HER-2/neu status in breast cancer." Fifth, another potential limitation to the use of both IHC and FISH in all cases is the increased cost associated with duplicate testing. Who is going to pay for this? Sixth, efforts are underway in both industry and the academic community to attempt to standardize IHC analysis for HER-2/neu. Although there have been concerns raised by us and others about the HercepTest (Dako Corp, Carpinteria, CA), ${ }^{2,4,5}$ we believe the development of this assay and its subsequent approval by the United States Food and Drug Administration represent important steps toward the standardization of HER-2/neu IHC, and the Dako Corporation should be commended for pursuing this important objective. Finally, in recognition of the current limitations in methods for $H E R-2 / n e u$ evaluation, the National Cancer Institute has organized a symposium to which experts in the fields of medical oncology, pathology, and biotechnology have been invited to discuss appropriate ways to identify

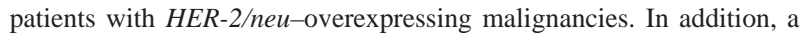
number of cooperative groups have undertaken studies to address these lingering questions.

In summary, how best to evaluate and report the HER-2/neu status of breast cancers remains a work in progress. Until the unresolved issues are resolved, pathologists and clinicians will need to determine the most appropriate method to assess the HER-2/neu status for breast cancer patients at their institutions, based upon the available data, technical considerations, and institutional expertise and resources.

Timothy W. Jacobs
Stuart J. Schnitt
Beth Israel Deaconess Medical Center
Harvard Medical School
Boston, MA
Allen M. Gown
Hadi Yaziji
PheonoPath Laboratories
IRIS
Seattle, WA

\section{REFERENCES}

1. Jacobs TW, Gown AM, Yaziji H, et al: Comparison of fluorescence in situ hybridization and immunohistochemistry for the evaluation of HER-2/neu in breast cancer. J Clin Oncol 17:1974-1982, 1999 
2. Jacobs TW, Gown AM, Yaziji H, et al: Specificity of HercepTest in determining HER-2/neu status of breast cancers using the United States Food and Drug Administration-approved scoring system. J Clin Oncol 17:1983-1987, 1999

3. Jacobs TW, Gown AM, Yaziji H, et al: HER2/neu protein expression in breast cancer evaluated by immunohistochemistry: A study of inter-laboratory agreement. Am J Clin Pathol (in press)

4. Roche P, Ingle J: Increased HER2 with U.S. Food and Drug Administration-approved antibody. J Clin Oncol 17:434, 1999 (letter)

5. Maia DM: Immunohistochemical assays for HER2 overexpression. J Clin Oncol 17:1650, 1999 (letter)

\section{Phase I Trial Dosing of Gemcitabine and Concurrent Involved Field Irradiation in Patients With Localized Pancreatic Carcinomas}

To the Editor: I happened to review the article by Blackstock et al in the July issue of the Journal of Clinical Oncology entitled "Phase I Trial of Twice-Weekly Gemcitabine and Concurrent Radiation in Patients With Advanced Pancreatic Cancer." ${ }^{1}$ It struck me that since there are prior trials using 800 or $1,000 \mathrm{mg} / \mathrm{m}^{2}$ much like a Byfield regimen with radiotherapy for pancreatic carcinoma, a dose of $40 \mathrm{mg} / \mathrm{m}^{2}$ given twice weekly is a very, very low dose. There may have been a dosage error. However, if I were to write a protocol on gemcitabine and pancreatic carcinoma using chemotherapy concurrently with radiotherapy and splitting up the dose, the dose would be $400 \mathrm{mg} / \mathrm{m}^{2}$ twice a week or 500 $\mathrm{mg} / \mathrm{m}^{2}$ twice a week. If this dose of $40 \mathrm{mg} / \mathrm{m}^{2}$ is the starting dose to be used to radiosensitize pancreatic carcinoma, it is an exceedingly small dose. I doubt it would be of any benefit over localized radiation therapy to the pancreas at all. Even if it is correct, I am not sure why the authors chose the dose.

John J. Nanfro Rome Hematology-Oncology Specialists, PC Rome, $G A$

\section{REFERENCES}

1. Blackstock AW, Bernard SA, Richards F, et al: Phase I trial of twice-weekly gemcitabine and concurrent radiation in patients with advanced pancreatic cancer. J Clin Oncol 17:2208-2212, 1999

In Reply: We thank Dr Nanfro for his interest in our recent article. ${ }^{1}$ It is important to realize that the gemcitabine effect, both its toxicity and efficacy, does not scale linearly when the schedule is altered. The twice-weekly maximum-tolerated dose of $40 \mathrm{mg} / \mathrm{m}^{2}\left(80 \mathrm{mg} / \mathrm{m}^{2} / \mathrm{wk}\right)$ established in our phase I trial, as pointed out in our Discussion, is consistent with the results reported by other investigators. Poplin et al, ${ }^{2}$ in a cohort of 29 patients with advanced cancers, observed the twice-weekly maximum-tolerated dose for gemcitabine, given without radiation over a 30 -minute infusion, to be $65 \mathrm{mg} / \mathrm{m}^{2}$. In a phase II study involving 90 non-small-cell lung cancer patients, Lund et $\mathrm{al}^{3}$ determined that twice-weekly gemcitabine at a dose of $90 \mathrm{mg} / \mathrm{m}^{2}$ resulted in response rates comparable to that reported with a $1,000 \mathrm{mg} / \mathrm{m}^{2}$ once-weekly dosing schedule.

Clearly, a number of studies indicate a relative biologic equivalence between a much lower gemcitabine dose given twice weekly and the higher dose given once weekly. Simply dividing the dose in half and delivering that dose twice weekly produces excessive toxicity.

In vitro and in vivo data from several laboratories have shown that gemcitabine has significant radiation-sensitizing activity at very low doses and that the sensitization is relatively short-lived. ${ }^{4-6}$ In addition, the strong radiation-sensitizing effect of gemcitabine, even administered once weekly, produces substantial toxicity when given at doses much lower than with the drug alone, as suggested by Nanfro. These data all support our approach of combining radiation with a more frequent gemcitabine dosing schedule in an effort to optimize the synergistic interaction. The data clearly show that the linear approach of simply dividing the dose would result in undue morbidity. This emphasizes the need to understand fully the drug action and interaction before designing phase I/II trials with radiation therapy.

\author{
A. William Blackstock \\ Wake Forest University \\ Winston-Salem, NC \\ Joel E. Tepper \\ University of North Carolina \\ Chapel Hill, NC
}

\section{REFERENCES}

1. Blackstock AW, Bernard SA, Richards F, et al: Phase I trial of twice-weekly gemcitabine and concurrent radiation in patients with advanced pancreatic cancer. J Clin Oncol 17:2208-2212, 1999

2. Poplin E, Corbett T, Flaherty L, et al: Difluorodeoxycytidine (dFdC)-gemcitabine: A phase I study. Invest New Drugs 10:165-170, 1992

3. Lund B, Ryberg M, Meidahl Petersen P, et al: Phase II study of gemcitabine $\left(2^{\prime} 2^{\prime}\right.$-difluorodeoxycytidine) given as a twice weekly schedule to previously untreated patients with non-small cell lung cancer. Ann Oncol 5:852-853, 1994

4. Blackstock AW, Bernard SA: Twice-weekly gemcitabine and concurrent radiation: Laboratory studies supporting phase I clinical trial in pancreatic cancer. Can Conf 3:2-6, 1999

5. Lawrence TS, Chang EY, Hahn TM, et al: Delayed radiosensitization of human colon carcinoma cells after a brief exposure to $2^{\prime}, 2^{\prime}$-difluoro-2'-deoxycytidine (gemcitabine). Clin Cancer Res 3:777782,1997

6. Lawrence TS, Chang EY, Hahn TM, et al: Radiosensitization of pancreatic cancer cells by $2^{\prime}, 2^{\prime}$-difluoro- $2^{\prime}$-deoxycytidine. Int J Radiat Oncol Biol Phys 34:867-872, 1996

\section{CD20-Negative Relapse After ${ }^{131}$ I-Anti-CD20 Therapy}

To the Editor: Micallef et $\mathrm{al}^{1}$ reported the development of a CD20negative peripheral T-cell lymphoma after therapy for B-cell lymphoma with the monoclonal anti-CD20 antibody rituximab in the April 1999 issue of Blood. In addition, there are two reports indicating the development of CD20-negative lymphomas after rituximab therapy. 2,3 We now wish to report a patient who relapsed with a CD20-negative lymphoma after radioimmunotherapy with ${ }^{131}$ I-labeled anti-CD20 monoclonal antibody. To our knowledge, this is the first reported case of CD20-negative large-cell lymphoma relapsing after radioimmunotherapy for a CD20-positive B-cell low-grade lymphoma.

A 73-year-old woman was diagnosed with non-Hodgkin's lymphoma, follicular mixed histology in 1992. She was treated with several chemotherapy regimens, including cyclophosphamide, vincristine, and prednisone; lomustine, vincristine, procarbazine, and prednisone; cyclophosphamide, doxorubicin, vincristine, and prednisone; and fludarabine (with and without prednisone). The last dose of chemotherapy she received was fludarabine in August 1998. A follow-up computed tomography scan in October 1998 revealed multiple small nodules 
within the lung, liver, and spleen. A liver biopsy did not reveal tumor or granuloma. In December 1998, the patient complained of weakness and low-grade fever but denied night sweats or weight loss.

In January 1999, she was referred to the Rush Cancer Institute, Chicago, IL, for radioimmunotherapy with ${ }^{131}$ I-labeled monoclonal anti-CD20 antibody (Bexxar; Coulter Pharmaceutical, Inc, South San Francisco, CA, and SmithKline Beecham, Philadelphia, PA). She had palpable lymph nodes in the right neck (about $2 \mathrm{~cm}$ ) and left axilla (1 to $1.5 \mathrm{~cm}$ ). Her leukocyte count was $2.7 \times 10^{6} / \mu \mathrm{L}$, her hemoglobin level was $11.3 \mathrm{~g} / \mathrm{dL}$, her hematocrit level was $33.9 \%$, her platelet count was $249,000 / \mu \mathrm{L}$, and her lactate dehydrogenase level was $742 \mathrm{U} / \mathrm{L}$ (range, 200 to $650 \mathrm{U} / \mathrm{L}$ ). A computed tomography scan showed left axillary, retroperitoneal, and pelvic lymphadenopathy, mild splenomegaly, and multiple lesions in the liver and spleen. Bilateral bone marrow biopsies revealed lymphoid aggregates consistent with lymphomatous infiltration, occupying $5 \%$ to $10 \%$ of the marrow. The aggregates consisted predominantly of small mature lymphocytes with irregular nuclear outlines admixed with a few large cells with prominent nucleoli. Immunostaining showed a predominance of CD20-positive B cells in these aggregates. The patient's serum was negative for human antimouse antibody.

The patient was eligible for the trial using Bexxar radioimmunotherapy and received treatment on February 19, 1999. At her routine 1-month follow-up, she reported feeling well; the physical examination revealed a $1-\mathrm{cm}$ lymph node in the right supraclavicular area. Two weeks later, she was admitted to the local hospital with complaints of extreme fatigue and fever. She was transferred to the Rush Cancer Institute, and the physical examination revealed markedly enlarged cervical, axillary, and inguinal lymphadenopathy, varying from 2 to 3 $\mathrm{cm}$ in size. Fine-needle aspiration of the cervical, axillary, and inguinal lymph nodes revealed large-cell lymphoma that was negative for CD20 by immunocytochemistry and flow cytometry. The patient was acidotic with markedly elevated lactic acid levels. Her lactate dehydrogenase level was 7,185 U/L, and the clinical picture was consistent with tumor lysis syndrome. She died of worsening acidosis and cardiorespiratory failure a day later. Unfortunately, molecular studies could not be done to evaluate the relationship between the transformed lymphoma and the original low-grade disease.

Although the aggressive large-cell lymphoma appeared after treatment with radiolabeled anti-CD20 antibody, a causal relationship is uncertain. This most likely represents a transformation from a lowgrade lymphoma, which is part of the natural history of this entity. The role of radioimmunotherapy in the transformation of this patient's lymphoma is unclear. However, the complete disappearance of the stainable CD20 antigen raises several interesting questions: (1) Circulating antibodies had been demonstrated in the patient's serum up to 6 months after therapy with rituximab. It is possible that these antibodies bind to the antigen epitopes and blocked the staining for CD20 by immunocytochemistry or flow cytometry. (2) Data from studies using retreatment with Rituxan ${ }^{4}$ (IDEC Pharmaceuticals, San Diego, CA) indicate that about half of the patients with B-cell non-Hodgkins lymphoma who initially responded to the antibody did not respond to the second course. Regrowth of CD20-negative lymphoma cells that escaped the initial therapy most likely explains this phenomenon. However, it is not clear whether the antibody has any role in acceleration of the growth of the antigen-negative cells, either by itself or by its effect on CD20-positive cells.

This case also emphasizes the importance of close observation of patients receiving biologic therapy. Biologic therapy usually takes a longer time than chemotherapy to produce an objective response. In rare cases, a transient worsening of lymphadenopathy may occur immediately after immunotherapy and before the response. Only by rigorous monitoring can this be differentiated from an indolent lymphoma that is undergoing transformation.

P. Venugopal
W.T. Leslie
T. O'Brien
S.A. Gregory
Rush Cancer Institute
Rush Presbyterian St Luke's Medical Center

Chicago, IL

\section{REFERENCES}

1. Micallef INM, Kirk A, Norton A, et al: Peripheral T-cell lymphoma following rituximab therapy for B-cell lymphoma. Blood 93:2427-2428, 1999

2. Kinoshita T, Nagai H, Murate T, et al: CD20-negative relapse in B-cell lymphoma after treatment with rituximab. J Clin Oncol 16:3916, 1998 (letter)

3. Maloney DG, Davis T, Levy R: Peripheral T-cell lymphoma after anti-CD20 antibody therapy: In reply. J Clin Oncol 16:1636-1637, 1998 (letter)

4. Davis T, Levy R, White CA, et al: Retreatments with Rituxan have significant efficacy, do not cause HAMA, and are a viable minimally toxic alternative in relapsed or refractory non-Hodgkin's lymphoma. Blood 90:509a, 1997 (abstr 2269, suppl 1)

\section{ERRATUM}

The September 1999 article by Yung et al, entitled "Multicenter Phase II Trial of Temozolomide in Patients With Anaplastic Astrocytoma or Anaplastic Oligoastrocytoma at First Relapse" (J Clin Oncol 17:2762-2771, 1999) contained two errors in the Appendix. The following corrections should be made to the Appendix that lists the participants in the Temodal Brain Tumor Study Group:

Dr. F. Lejeune's institution is the Centre Pluridisciplinaire d'Oncologie, CHUV, Lausanne, Suisse.

Dr. P-Y. Dietrich of the Division Oncologie-Hematologie, Hopital Cantonal, Geneva, Suisse, was omitted and should be included. 